\title{
Expanding Medicaid Coverage for Community-Based Long-Term Services and Supports: Lessons from Maryland's Community First Choice Program
}

\author{
Julia Burgdorf, BS \\ Jennifer L. Wolff, $\mathrm{PhD}$ \\ Amber Willink, PhD \\ Cynthia Woodcock, MBA \\ Ian Stockwell, PhD \\ Karen Davis, $\mathrm{PhD}$
}

\begin{abstract}
Community First Choice (CFC) is a Medicaid state plan option authorized through the Affordable Care Act (ACA) that supports the delivery of long-term services and supports in home and community settings. We interviewed stakeholders in Maryland, one of the first states to adopt CFC, to assess challenges, benefits, and potential implications of this Medicaid option for state and federal policymakers. Study findings suggest that expanding coverage for homeand community-based services through CFC in Maryland has been financially feasible, expanded the personal care workforce, and supported a more equitable approach to personal care services. We conclude that greater coverage for home- and community-based long-term services is a promising avenue to improve access to care for high-need Medicaid beneficiaries.
\end{abstract}




\section{Introduction}

Most persons with disabilities live in the community with supportive services and help provided by family, friends, or paid personal attendants. Medicaid finances the care needs of millions of Americans and is the primary payer for long-term services and supports (LTSS) in the U.S. (Favreault \& Dey, 2015). However, significant variation exists in state Medicaid approaches to community-based LTSS coverage (Houser, Fox-Grage, \& Ujvari, 2012; AARP Foundation, 2017).

Community First Choice (CFC) is a program created by the Affordable Care Act (ACA) that gives states the option to expand Medicaid coverage for HCBS. Through CFC, states can fund home-based assistance for beneficiaries with disabilities in self-care and household activities, as well as related support services including case management and home modification (Centers for Medicare and Medicaid Services (CMS), 2012; US Department of Health \& Human Services, 2015). Participating states receive an additional 6 percentage point Federal Medical Assistance Percentage (FMAP), the federal government's contribution to each state's Medicaid spending, for approved CFC services (CMS, 2012). CFC is a state plan benefit, meaning that personal care coverage is written into the state's Medicaid benefits rather than as a waiver that is targeted to a specific subpopulation with limits on enrollment. Although waivers confer greater budgetary control to states, they also introduce administrative complexity and may lead to confusion among beneficiaries that inhibits access to care and leads to inequitable distribution of benefits.

This paper extends prior reports by examining Maryland's experience with CFC. Maryland was one of the first states to implement CFC (in 2014) and is a notable case study given availability of other HCBS programs such as 1915(c) waivers, a Money Follows the Person demonstration, and a state plan personal care option prior to CFC implementation (NORC at The 
University of Chicago, 2014; The Hilltop Institute, 2014). In this study, we provide an overview of CFC, describe Maryland's CFC experience, and present key insights on the program's challenges and benefits gleaned from stakeholder interviews to inform other states who may be interested in expanding HCBS infrastructure (Davis, Willink, \& Schoen, 2016). Findings are especially timely considering current discussion regarding the programmatic structure of Medicaid within the context of broader health reform (Sommers \& Grabowski, 2017).

\section{CFC Uptake among the States}

$\mathrm{CFC}$ is a recent development in a long-standing effort to expand access to HCBS. Historically, states have expanded access to HCBS through 1915(c) waiver programs and the state plan personal care option. More recently, the ACA introduced Money Follows the Person, the Balancing Incentive Program, and CFC, all of which provide alternatives for state Medicaid authorities to provide HCBS with enhanced federal support. (CMS, n.d.; Karon et al, 2016; Irvin et al, 2017; Ng, Harrington, Musumeci, \& Ubri, 2016).

To date, eight states—CA, CT, MD, MT, NY, OR, TX, and WA—have implemented CFC and four states have submitted pending applications (National Association of States United for Aging and Disabilities, 2017; "Section 1915(k)", 2016). Previous work suggests that state leaders have been hesitant to implement CFC due to concerns that demand for personal care may outpace state budgetary allotments and that expanded HCBS coverage may be hampered by workforce shortages (US Department of Health \& Human Services, 2015; US Government Accountability Office, 2012). Additionally, as unpaid family caregiving is a crucial source of support for the Medicaid population, fear that expanding payment for personal care could erode unpaid caregiving has been cited as one reason for diminished interest in CFC adoption by some 
state Medicaid administrators (National Association of States United for Aging and Disabilities, 2017; McMaughan-Moudouni, Ohsfeldt, Miller, \& Phillips, 2012; van Houtven \& Norton, 2004;

Weissert, 1985; Torres, Kietzman, \& Wallace, 2015).

\section{Study Data \& Methods}

This analysis was undertaken as part of a mixed methods study of Maryland's CFC program that involved in-depth interviews with stakeholders and an analysis of CFC enrollment, expenditures, and unpaid caregiving trends. In-depth interviews were conducted with ten subjects from the American Association of Retired Persons, the National Association of Medicaid Directors, Maryland Department of Health and Mental Hygiene, and the Maryland Community First Choice Patient Advisory Committee. These individuals were identified via personal contacts of the investigators, recommendations by key state officials, and chain-referral sampling in which interview subjects were asked to identify other key informants with important perspectives on this topic.

An initial interview guide was constructed with the input of subject matter experts. Questions were designed to elicit information on the goals, design, and implementation experiences of the Maryland CFC program. Topics included motivating factors leading to CFC program development and benefit design, approach to cost containment, and impact on the personal care workforce (paid and unpaid). With the knowledge and permission of subjects, all interviews were recorded, and reviewed and transcribed afterwards. The Johns Hopkins Bloomberg School of Public Health Institutional Review Board reviewed the protocol for this study and deemed it to be exempt from IRB review, given minimal risk to participants.

Research team members reviewed transcripts to identify emerging themes and note knowledge gaps to inform future interviews. Inductive analysis was used to develop inferences 
regarding CFC and Medicaid expansion of HCBS more broadly, focusing on challenges previously identified in federal reports, including quality oversight, workforce availability, and budgeting. (US Department of Health \& Human Services, 2015; US Government Accountability Office, 2012). Emphasis was given to themes and conclusions that were voiced independently by multiple interviewees.

\section{Study Results: Maryland's Community First Choice Experience} Impetus for CFC Adoption

Key informants reported that leaders in the Maryland Department of Health pursued CFC to improve the state's HCBS infrastructure by expanding coverage, standardizing and strengthening personal care benefits, and increasing the community-based caregiver workforce capacity. The additional FMAP helped make CFC an attractive option for expanding coverage of home-based LTSS and related supports.

"It's a strong argument to say there's federal money on the table and we should take it, because we've been unbalanced in our approach to institutional versus home-based care."

_Former Official, Maryland Department of Health

Prior to adopting CFC, Maryland operated multiple Medicaid waiver options for home- and community-based LTSS as well as the Medical Assistance Personal Care (MAPC) benefit in the state plan (NORC at The University of Chicago, 2014). In addition to the MAPC benefit, personal care was included as a service in various other waiver programs and payment rates for personal care attendants varied significantly across the programs. The state viewed CFC as a 
mechanism for standardizing personal care services and payment rates, transitioning enrollees who were receiving these services from various waivers or state programs into a cohesive state plan benefit. The ability to standardize HCBS as a state plan option, along with the increased FMAP, were important reasons why Maryland Medicaid leaders elected to implement CFC.

"What grew from the waivers was a system with six different payment rates for personal assistance services, different methods of administration, different roles for local health departments... we had huge variety among the programs, for essentially the same service to the same population. Whichever program [a beneficiary] happened to encounter first determined their service package, rather than their level of need determining their service package.”-Long-Term Services and Supports Official, Maryland Department of Health

Stakeholders reported CFC was viewed as a means of enhancing the HCBS workforce. CFC would offer a state plan personal care benefit with no waiting lists, thus expanding coverage and incenting HCBS workforce entry. Additionally, CFC program design includes an option for states to pay enrollees' family caregivers for personal care services, either directly or via an agency model, supporting person-centered care by giving enrollees greater choice in personal care providers. Medicaid officials viewed development of the personal care workforce as a foundational step towards other innovative programs that rely on HCBS, such as demonstrations for dual eligible beneficiaries and managed LTSS.

Maryland Medicaid made several changes to standardize and improve service packages when implementing CFC. Changes to the state's approach to HCBS coverage and administration, 
service plan development, and family caregiver compensation, as well as the concomitant challenges for state administrators, are discussed in the following section.

\section{Program Implementation: Tradeoffs in Oversight and Flexibility}

A theme throughout stakeholder interviews was a common refrain in Medicaid HCBS discussions more broadly: the tension between necessary state oversight and respect for the enrollees' autonomy and individuality. States must maintain oversight to ensure care quality and effectively manage the overall service budget. However, HCBS programs must also be flexible, to provide enrollees maximal autonomy and facilitate plans of care that scale up or down to meet individual needs. While this tension is not specific to CFC or to Maryland, Maryland's experience is an illustration of how state Medicaid leaders can balance these competing concerns during an expansion of HCBS.

\section{Shifting Quality Control from Local- to State-Level}

Maryland local health department staff were concerned about ensuring care quality under CFC due in part to the shift of supervision responsibilities from local departments of aging and disabilities (historically responsible for administration of personal care services) to the state Medicaid office as these services were incorporated into the statewide CFC program.

"There were a lot of locus of control changes. The local health departments had complete control over our personal care benefits and we were pulling that away from them and changing their role, so there was anxiety." - Long-Term Services and Supports Official, Maryland Department of Health 
State administrators reported communicating frequently with local agency leaders, noting that greater transparency helped assuage concerns. Additionally, the state invested in quality assurance by supporting a nurse monitoring program and conducting regular data audits to monitor care quality and detect fraud. State employees monitor the program with the help of reports generated through a newly developed LTSSMaryland data warehouse which includes enrollee assessments, claims data, case management information, nurse monitoring reports, and additional billing records ("In-Home Supports", n.d.). State employees—both nurses and administrative staff - may access this information to support ongoing care-planning and quality monitoring efforts.

State leaders noted the need for additional staff to keep pace with the administrative work of approving plans of care; a responsibility previously held at the local level. State officials brought in temporary employees to manage the initial influx and reflect that other states should consider hiring additional staff before shifting control from local- to state-level entities, in anticipation of a significant increase in administrative workload.

“We underestimated how much work approving the plans of care would be... we couldn't have done it without the additional staffing."

—_ong-Term Services and Supports Official, Maryland Department of Health

\section{Ensuring Access while Safeguarding the State Budget}

Key informants reported that officials designed a method for assigning flexible, acuity-based service budgets to constrain costs. Maryland officials constructed seven flexible budget groups 
by taking the annual personal assistance budget in relation to the estimated number of enrollees and adjusting for acuity so that higher budget suggestions were afforded to higher acuity enrollees. When developing individual service plans with a case manager, each enrollee is assigned an acuity group based on the Resource Utilization Group (RUG) score generated from local health department's interRAI assessment and the interRAI-HC algorithm. (Tucker, 2009; "Instruments", 2017; Maryland Department of Health and Mental Hygiene, 2015). The objective of budget guidelines is to facilitate tailored service plans appropriate to individual enrollees' level of need while minimizing the likelihood of overutilization and unnecessary expenditures.

“[The budget] is a guideline but we don't expect that it's followed strictly. [Before CFC] we didn't have a good way of measuring acuity and linking that to services because the waiver program determined how much money each person got, rather than their need ... now with a standardized service planning and approval process we can improve this approach over time." —Long-Term Services and Supports Official, Maryland Department of Health

Thus far, the new method of allocating the CFC budget has helped service planning agencies manage costs while ensuring enrollees receive necessary services. Service planning agencies are informed of each CFC enrollee's assessment and relevant budget category to aid in the development of a plan of care. Enrollees and case managers work together to develop individual service plans. Case managers use the budget as a guide, but have the flexibility to apply for additional funding based on each enrollee's specific needs. According to Maryland Department of Health internal data, 94\% of applications for budget exceptions are approved (Nawara, 2014). 


\section{Balancing Enrollee Choice and Administrative Feasibility}

Key informants in Maryland reported that adequate workforce availability has not been a problem in CFC. However, the state has faced a tradeoff between enrollees' autonomy in choosing their caregiver and the state's ability to directly oversee and administer payment to caregivers. CFC allows states to either pay caregivers directly and/or to pay licensed home care agencies for services provided by their employees. Officials initially planned to include both options in the Maryland CFC program.

A June 2014 interpretation of the Fair Labor Standards Act (FLSA) issued by the Department of Labor had financial and administrative ramifications for state Medicaid agencies (Weil, 2014). The FLSA includes protections and regulations relating to private- and public-sector employment, including definitions of which workers are eligible for overtime payment (US Department of Labor, 2016). This interpretation affected the design of CFC in Maryland by prohibiting "third party employers of domestic service employees-i.e., employers other than the individuals receiving services ... from claiming the companionship services exemption from minimum wage and overtime" (Weil, 2014). Maryland Medicaid would be considered a third party employer for caregivers under the self-directed option, leading to administrative and fiscal challenges including reimbursing travel time between multiple care recipients (an administrative challenge requiring meticulous parsing of claims data) and overtime (a difficulty given the inability to define when a live-in family caregiver is "off-duty").

Given these expectations, along with competing Department of Heath priorities related to implementation of a statewide insurance exchange and payment reforms for behavioral health care, Maryland Medicaid leaders did not have the capacity to incorporate direct caregiver payment and the state shifted to agency care only in the CFC program. Enrollees may still 
receive services from a family member or aide designated as their caregiver, provided that caregivers are employed by a licensed agency.

Allowing CFC enrollees to designate their preferred caregiver offers financial support to family caregivers already delivering LTSS. Additionally, Maryland officials reported that it was important from a personal autonomy standpoint to give enrollees the opportunity to choose their caregiver. Howver, many states worry that offering payment to those previously serving as unpaid caregivers could lead to a substitution of paid for unpaid care, eroding the hours of unpaid care Medicaid enrollees receive. Based on communication with local health departments and the CFC Patient Advisory Council, key informants did not report noticeable declines in unpaid caregiving in Maryland associated with CFC implementation.

"You can think about this as a family values, personal autonomy issue. These are very intimate services and you want to pick the person who is going to help change you and toilet you." -Former Official, Maryland Department of Health

\section{Discussion}

Maryland's early experience with CFC implementation offers important insights for expanded home- and community-based LTSS. Maryland Medicaid leaders reported that expanded LTSS coverage through CFC has strengthened the state's HCBS infrastructure and workforce capacity. Findings from a recent report issued by The Hilltop Institute provide additional insight in finding that Maryland's CFC expenditures increased in parallel with enrollment, from $\$ 140.5$ million in 2014 to $\$ 247.5$ million in 2016 , but that per member per year spending remained relatively constant at roughly $\$ 21,000$, with the majority of spending (87\%) devoted to personal assistance services. However, unpaid caregiving was and continues to be the 
predominant source of assistance to individuals enrolled in CFC: average weekly hours of unpaid caregiving were reported to be 35.9 hours before CFC implementation and 28.3 hours one-year after initiation of CFC services (Whiton \& Stockwell, 2017).

In 2016, 11,573 Maryland Medicaid beneficiaries participated in CFC (Whiton \& Stockwell, 2017). Despite widespread need for LTSS outside of institutional settings, concern about unanticipated enrollment growth and related costs for a new state plan benefit that must be provided to all who are eligible has tempered interest in expanding coverage for home and community-based services through CFC in other states (The Hilltop Institute, 2014; Freedman \& Spillman, 2014). Key informants in Maryland indicated that while the introduction of CFC has been accompanied by enrollment growth, the interRAI-based budget guidelines put into place during CFC implementation are helping the state to manage this growth, an assertion supported by The Hilltop Institute's finding that per member per year spending has remained stable (Whiton \& Stockwell, 2017). Stakeholders noted areas in which additional care was needed to balance state oversight with program flexibility and enrollee autonomy, including quality control, budgetary oversight, and caregiver selection. This delicate equilibrium can be difficult to achieve and warrants continued research and discussion by policymakers and advocates.

\section{Conclusion}

Maryland's experience with Community First Choice suggests that programs which expand Medicaid coverage for HCBS and personal care have promise as a means of improving needed access to LTSS. Given shifting political realities, future federal support for CFC is uncertain. However, demographic trends and the aging of the post-WWII boomer population portend growing need for home-based LTSS in the decades to come. CFC and similar programs 
to expand access to HCBS have potential to improve access to needed services while supporting beneficiary autonomy and well-being.

\section{Acknowledgements}

Authors wish to thank leaders at the Maryland Department of Health for their time and insight.

\section{References}

AARP Foundation. Long-term services and supports state scorecard. (n.d.). Retrieved from: http://www.longtermscorecard.org/

Centers for Medicare and Medicaid Services. (n.d.). Home \& Community-Based Services 1915(c ). Retrieved from: https://www.medicaid.gov/medicaid/hcbs/authorities/1915-c/index.html

Centers for Medicare and Medicaid Services. (2012). Medicaid Program, Community First Choice Option. Federal Register, 77(88), 26828-26903.

Davis K, Willink A, Schoen C. (2016). Medicare Help at Home. Retrieved from: http://healthaffairs.org/blog/2016/04/13/medicare-help-at-home/

Favreault M \& Dey J. (2015). Long-Term Services and Supports for Older Americans: Risks and Financing Research Brief. Washington DC: Assistant Secretary for Planning and Evaluation. Retrieved from:

https://aspe.hhs.gov/basic-report/long-term-services-and-supports-older-americans-risks-and-financing-researchbrief

Freedman V \& Spillman B. (2014). Disability and Care Needs Among Older Americans. The Milbank Quarterly, 92, 509-541. doi:10.1111/1468-0009.12076

$10.1111 / 1468-0009.12076$

The Hilltop Institute. (2014). Medicaid Long-Term Services and Supports in Maryland: FY 2009 to FY 2012. Retrieved from: http://www.hilltopinstitute.org/publications/DHMHLTSSChartbookVol1-August2014.pdf

Houser A, Fox-Grage W, Ujvari K. (2012). Across the states: Profiles of long-term services and supports. AARP Public Policy Institute. Retrieved from:

http://www.aarp.org/content/dam/aarp/research/public_policy_institute/ltc/2012/across-the-states-2012-full-reportAARP-ppi-ltc.pdf

In-Home Supports Assurance System (ISAS). (n.d.). Maryland Department of Health and Mental Hygiene.

Retrieved from:

https://mmcp.dhmh.maryland.gov/longtermcare/Resource\%20Guide/05.\%20ISAS/Additional\%20FAQs\%20and\%2

0Contact\%20Resources/ISAS\%20FAQ\%20Provider\%20Issues\%20CFC+CO\%20Providers.pdf

Instruments: An overview of the interRAI suite. (2017). interRAI. Retrieved from:

http://www.interrai.org/instruments/

Irvin C, Bohl A, Stewart K, Williams SR, Steiner A, Denny-Brown N, et al. (2017). Final report: Money follows the person 2015 annual evaluation report. Mathematica Policy Research. Retrieved from:

https://www.medicaid.gov/medicaid/ltss/downloads/money-follows-the-person/mfp-2015-annual-report.pdf 
Karon S, Knowles M, Lyda-McDonald B, Thach T, Wiener J, Justic D, et al. (2016). Final process evaluation of the Balancing Incentive Program. US Department of Health and Human Services: Office of the Assistant Secretary for Planning and Evaluation. Retrieved from: https://aspe.hhs.gov/pdf-report/final-process-evaluation-balancingincentive-program

Maryland Department of Health and Mental Hygiene. (2015). Community First Choice and Community Options Report: October 2015. Retrieved from: https://mmcp.health.maryland.gov/Documents/CFCcommunityoptionsJCRfinal10-15.pdf

McMaughan-Moudouni D, Ohsfeldt R, Miller T, Phillips C. (2012). The Relationship between Formal and Informal Care among Adult Medicaid Personal Care Services Recipients. Health Services Research, 47(4),1642-1659. doi:10.1111/j.1475-6773.2012.01381.x.

Nawara L. (2014). Community First Choice [Powerpoint slides]. Maryland Department of Health and Mental Hygiene. Retrieved from http://www.mdgerontology.org/pdfs/2014SpringConferenceDocs/CFC_DOL_Overview2014.ppt

National Academies of Sciences, Engineering, and Medicine. (2016). Families caring for an aging America. Washington, DC: National Academies Press. doi: 10.17226/23606.

National Association of States United for Aging and Disabilities. (2017). State Medicaid integration tracker. Retrieved from: http://www.nasuad.org/sites/nasuad/files/State\%20Medicaid\%20Integration\%20Tracker\%20June\%202017.pdf

Ng T, Harrington C, Musumeci M, Ubri P. (2016). Medicaid Home and Community-Based Services Programs: 2013 Data Update. Kaiser Family Foundation. Retrieved from: http://www.kff.org/medicaid/report/medicaid-home-andcommunity-based-services-programs-2013-data-update/

NORC at the University of Chicago. (2014). ACA section 2401 Community First Choice option (section 1915(k) of the Social Security Act); Maryland state plan amendment summary. Retrieved from: https://www.medicaid.gov/medicaid/hcbs/downloads/md-cfc-spa-matrix.pdf

Section 1915(k) community first choice state plan option. (2016). Kaiser Family Foundation. Retrieved from: http://www.kff.org/medicaid/state-indicator/section-1915k-community-first-choice-state-planoption/?currentTimeframe $=0 \&$ sortModel=\%7B $\% 22$ colId $\% 22: \% 22$ Location $\% 22, \% 22$ sort $\% 22: \% 22$ asc $\% 22 \% 7 \mathrm{D}$

Sommers B, Grabowski D. (2017). What Is Medicaid? More Than Meets the Eye. JAMA, 318(8), 695-696. doi:10.1001/jama.2017.10304

Reaves E \& Musumeci M. (2015). Medicaid and long-term services and supports: A primer. Kaiser Family Foundation. Retrieved from: http://www.kff.org/medicaid/report/medicaid-and-long-term-services-and-supports-aprimer/

Rosenbaum S. (2000). The Olmstead decision: Implications for Medicaid. Kaiser Commission on Medicaid and the Uninsured. Retrieved from: https://kaiserfamilyfoundation.files.wordpress.com/2000/03/2185-the-olmsteaddecision-implications-for-medicaid.pdf

Torres J, Kietzman K, Wallace S. (2015). Walking the line: Navigating market and gift economies of care in a consumer-directed home-based care program for older adults. The Milbank Quarterly, 93(4), 732-760. doi:10.1111/1468-0009.12163.

Tucker A. (2009). Resource Utilization Groups (RUGS). The Hilltop Institute. Retrieved from: http://www.hilltopinstitute.org/publications/ResourceUtilizationGroups-RUGs-September2009.pdf 
US Department of Health and Human Services: Office of the Secretary. (2015). Community first choice: Final report to Congress. Retrieved from: https://www.medicaid.gov/medicaid/hcbs/downloads/cfc-final-report-tocongress.pdf

US Department of Labor. (2016). Handy reference guide to the Fair Labor Standards Act. Retrieved from: https://www.dol.gov/whd/regs/compliance/hrg.htm

US Government Accountability Office. (2012). Medicaid: State's plans to pursue new and revised options for homeand community-based services. Retrieved from: http://www.gao.gov/assets/600/591560.pdf

van Houtven C, Norton E. (2004). Informal care and health care use of older adults. Journal of Health Economics, 23(6), 1159-1180. doi: 10.1016/j.jhealeco.2004.04.008

Weil D. (2014). Administrator's interpretation no. 2014-2. United States Department of Labor. Retrieved from: https://www.dol.gov/WHD/opinion/adminIntrprtn/FLSA/2014/FLSAAI2014_2.pdf

Weissert W. (1985). Seven reasons why it is so difficult to make community-based long-term care costeffective. Health Services Research, 20(4), 423-433.

Whiton K \& Stockwell I. (2017). Community First Choice Implementation in Maryland, 2014-2016. The Hilltop Institute. Retrieved from: http://www.hilltopinstitute.org/publications/CFCImplementationInMD-DataBriefSept2017.pdf 